\title{
Title: Lactoferrin as potential preventative and treatment for COVID-19
}

\author{
Raymond Chang ${ }^{1,2}$, Wei-zen Sun ${ }^{2,3}$, and Tzi Bun Ng${ }^{4}$ \\ ${ }^{1}$ PREreview \\ ${ }^{2}$ Institute of East West Medicine \\ ${ }^{3}$ National Taiwan University \\ ${ }^{4}$ Chinese University of Hong Kong
}

April 28, 2020

\begin{abstract}
The novel coronavirus 2019 (COVID-19) pandemic is rapidly advancing across the globe despite drastic public and personal health measures. Antivirals and nutritional supplements have been proposed as potentially useful against SARS-CoV-2 (virus that causes COVID-19), but few have been clinically established. Lactoferrin (Lf) is a naturally occurring and non-toxic glycoprotein that is orally available as a nutritional supplement and has established in vitro anti-viral efficacy against a wide range of virus including SARS-CoV, a closely related corona virus to SARS-CoV-2 (virus that causes COVID-19). Furthermore, Lf possesses unique immunomodulatory and anti-inflammatory effects that may be especially relevant to the pathophysiology of severe COVID-19 cases. We review the underlying biological mechanisms of Lf as antiviral and immune regulator, and propose its unique potential as a preventative and adjunct treatment for COVID-19. We hope that further research and development of Lf nutritional supplementation would establish its role for COVID-19.
\end{abstract}

\section{Introduction}

Since its initial reported outbreak in late 2019 (Zhu et al., 2020), corona virus 2019 (COVID-19) has exploded from a few people suffering from a respiratory disease in the Chinese city of Wuhan to a surging pandemic affecting hundreds of thousands around the globe. Current methods of pandemic control are confined only to public containment and private hygiene measures, while there are yet no established antiviral treatments and vaccine development may take as long as 18 months away (Kuchler et al., 2020).

Lactoferrin (Lf) is a naturally occurring and non-toxic glycoprotein that has been studied against a broad range of viruses including SARS-CoV, which is closely related to SARS-CoV-2 that causes COVID-19 (Chen et al., 2020). Furthermore, it has immunomodulatory and anti-inflammatory characteristics which can positively modify host responses to infections (Legrand et al., 2006). Lf is available as an oral supplement, and studies suggest that supplemental Lf may treat or prevent a host of microbial infections (Bruni et al., 2016). Here we examine the antiviral properties and immunomodulatory mechanisms of Lf within the context of its potential applications against SARS-CoV-2 and propose the possibility of supplemental Lf as a potential preventative and adjunct treatment for COVID-19, a condition whose pathophysiology involves both viral infection and an excessive host response (Fung et al., 2020).

\section{Lactoferrin}

Lactoferrin (Lf) is a highly conserved pleiotropic iron-binding glycoprotein of the transferrin family that is expressed and secreted by glandular cells and found in most body fluids (Levay \& Viljoen, 1995). It appears in especially high concentrations in mammalian milk and was first identified in bovine milk (Soerensen, M, 
1939) and subsequently isolated from human milk (Johanson et al., 1960). It has been found to be a 80-kDa glycoprotein containing 703 amino acid residues, and its primary structure has been well characterized (Jolles et al., 1984).

Since its discovery, Lf and its related peptides are mainly considered to be important non-specific host defense molecules against a variety of pathogens including a spectrum of viruses (Bruni et al., 2016). More recently, Lf's anti-inflammatory and immunomodulatory role has captured increasing scientific interest, since it appears to be able to moderate host response to infections and has the dual ability to stimulate the immune system to counteract pathogenic invasion while simultaneously preventing harmful host immune and inflammatory responses.

\subsection{Lf as a broad-spectrum antiviral agent}

The antiviral activity of Lf was first demonstrated in mice infected with the polycythemia inducing strain of the Friend virus complex in 1980s (Lu et al., 1987). Since the 1990s, the list of Lf susceptible pathogenic human viruses found to be inhibited by Lf have expanded to include naked and enveloped viruses, DNA and RNA viruses: cytomegalovirus, herpes simplex virus, human immunodeficiency virus (HIV), rotavirus, poliovirus, respiratory syncytial virus, hepatitis $\mathrm{B}$ and $\mathrm{C}(\mathrm{HCV})$ viruses, parainfluenza virus, alphavirus, hantavirus, human papillomavirus, adenovirus, enterovirus 71, echovirus 6, influenza A virus, and Japanese encephalitis virus, with the in vitro $\mathrm{EC}_{50}$ (effective concentration) of Lf's generally to be in the micromolar range against the viruses (Ng et al., 2015)(Wakabayashi et al., 2014). Particularly relevant to our review is the ability of Lf to inhibit pseudotyped SARS-CoV with a $50 \%$ inhibitory concentration $\left(\mathrm{IC}_{50}\right)$ of $0.7 \mu \mathrm{M}$ (Lang et al., 2011) since it is the human coronavirus that is most closely related with SARS-CoV-2 which causes COVID-19.

The ability of Lf to inhibit viral entry may be via binding to cell surface molecules or viral particles or both. Current research has revealed that viral entry is a highly complex process that involves cell surface molecules (Spear, 2004), with virus attachment followed by binding to a high-affinity cell surface receptor to initiate cell entry (Sapp \& Bienkowska-Haba, 2009). Heparan sulfate proteoglycans (HSPGs) have been identified as initial adhesion molecules for a number of viruses to increase their concentration at the cell surface and improve their odds of binding a more specific entry receptor and studies demonstrate Lf's role in preventing viral entry by binding to HSPG's (Andersen et al., 2004). Lf can also bind directly to virus particles as in HCV to divert them from target cells (Nozaki et al., 2003).

Besides reducing viral entry, Lf can also suppresses virus replication after the virus enters the cell as in the case of HIV (Puddu et al., 1998). Thereafter, Lf can also exert an indirect antiviral effects on immune cells that play a crucial role in the early stages of viral infections.

In human oral supplementation studies against pathologic viruses, Lf given in the range of 100-1000mg per day in humans was found to reduce the incidences of colds (Vitetta et al., 2013), and cold-like symptoms (Oda et al., 2012), as well as ameliorate rotaviral gastroenteritis (Egashira et al., 2007). In HCV patients, a randomized control study involving 111 patients receiving Lf vs. no Lf along with standard anti-HCV drugs demonstrated significant decrease of HCV viral titer and sustained virologic response in the Lf group (Kaito et al., 2007).

\subsection{Lf as an immunomodulatory and anti-inflammatory agent}

Lf is a unique multifunctional moiety which is not only a broad-spectrum antiviral, but has immunomodulatory (Siqueiros-Cendón et al., 2014) and anti-inflammatory (Baveye et al., 1999) actions that may play a role in the pathophysiology of severe infections. The key immunomodulatory role of this protein stems from its unique potential to maintain immune and physiological homeostasis and limit tissue damage by modulation of cytokines, chemokines, and cell surface receptors involved in cascades of signaling pathways (Actor et al., 2009). The myriad of biological pathways of control and feedback interactions with Lf has been extensively reviewed (Kruzel et al., 2017). Specific examples of Lf's balancing and restorative role is perhaps illustrated in the context of systemic inflammatory response syndrome (SIRS) which describes the complex physiologic 
response to severe insults such as sepsis as defined by a consensus conference in 1991 (Bone et al., 1992). An updated and overlapping concept of 'cytokine storm' similarly reflects hyper-induction of inflammatory responses resulting from unchecked immune activation (Behrens \& Koretzky, 2017), which Kruzel's group and others have proposed Lf might treat (Actor et al., 2009).

Injection of lipopolysaccharide (LPS) into animals reproduces the pathophysiologic changes induced by bacteria, and it is considered a standard model for sepsis. Using this model, it was demonstrated that Lf treatment reduced or eliminated many biological reactions normally seen upon LPS administration in a dose dependent manner (Kruzel et al., 2010), and in an earlier study, a single dose of lactoferrin before LPS injection reduced the mortality of mice to $16.7 \%$ from $83.3 \%$ in controls (Kruzel et al., 2000).

Given promising laboratory and animal studies, Lf has been investigated in a number of clinical settings against sepsis. Recently, a meta-analysis of 10 randomized controlled trials involving 3,679 infants concluded that Lf reduces late onset sepsis in pre-term infants (Razak \& Hussain, 2019). Separately, a human recombinant Lf talactoferrin was studied in a phase 2 clinical trial to assess outcome in severe sepsis and found a $12.5 \%$ reduction in all cause mortality in those treated (Guntupalli et al., 2013), but the results were regrettably not replicated in a follow-up phase $2 / 3$ trial (Vincent et al., 2015).

\subsection{LF as potential preventative and treatment of COVID-19}

Lf has been found to experimentally inhibit viral entry via binding to host cell surface HSPGs in murine coronavirus (de Haan et al., 2005), and human coronaviruses hCOV-NL63 (Milewska et al., 2014) and pseudotyped SARS-CoV (Lang et al., 2011). There are as yet no published studies on Lf effects on SARSCoV-2 and its entry into host cells. Nevertheless, given the currently accepted 'viral surfing' model for the role of cell surface HSPGs (Burckhardt \& Greber, 2009), that the invading virion particles 'surf' from low affinity HSPG anchoring sites to high affinity entry receptors in an invasion, together with the homology of SARS-CoV and SARS-CoV-2 spike protein structures, as well as both viruses depending on the same ACE2 receptor for cell entry (Hoffmann et al., 2020), we feel safe to postulate a similar mechanism whereby HSPGs serve as SARS-CoV-2 attachment sites that congregate the virus on the cell surface and facilitate specific entry receptors such as ACE2. It is thus likely that Lf can inhibit SARS-CoV-2 invasion at micromolar concentrations and in a dose dependent manner just as in the case of SARS-CoV (Lang et al., 2011).

Another major aspect of Lf bioactivity relates to its immunomodulatory and anti-inflammatory functions. In the case of viral infections in particular, it is often the magnitude of immune response and inflammation which contributes to disease severity, and this is particularly relevant for COVID-19.

Current thinking suggests that mortality from COVID-19 is not simply due to viral infection but is a result of a cytokine storm syndrome in select patients associated with hyper-inflammation leading to acute respiratory distress and subsequent mortality (Mehta et al., 2020). A cytokine profile in severe COVID-19 cases is characterized by increases in cytokines and acute phase reactants such as interleukin IL-6, tumor necrosis factor- $\alpha(\mathrm{TNF} \alpha)$ and ferritin. In this regard, Lf is demonstrated to reduce IL-6, TNF $\alpha$ (Zimecki et al., 1998), and downregulate ferritin (Rosa et al., 2017) in experimental settings simulating sepsis. If the hypothesis that Lf can modulate an overactive immune and inflammatory response to viral infection is correct, then Lf could be a candidate adjunct treatment for more severe cases of COVID-19.

\section{Discussion}

Lf can be recombinant or naturally derived from bovine or mammalian sources, and is considered by the FDA as 'generally regarded to be safe" (GRAS) with no contraindications. It is widely used as a nutritional additive in infant formulas and clinical studies employed Lf doses ranging from $100 \mathrm{mg}$ to $4.5 \mathrm{~g}$ a day for various indications without apparent toxicities. Newer formulations of Lf including encapsulation and liposomalization have been explored (Ishikado et al., 2005),

and Lf derivatives and related peptides such as lactoferricin and lactoferrampin with more potent antiviral properties are being explored and developed (Bruni et al., 2016). 
One observation regarding the clinical epidemiology of the current COVID-19 pandemic that may be relevant to Lf was the relatively low incidence of the infection in children. Indeed, it has been reported that the incidence of COVID-19 in children aged 0-10 was only 0.9\% in the Chinese cases reported (Hong et al., 2020). COVID-19 cases were rarer still in neonates and infants with a total of only 9 infected and hospitalized cases in China between December 82019 and February 62020 out of a total 31,211 reported cases nationwide (Wei et al., 2020). Moreover the course in infants was mild even upon infection with none of the 9 reported cases above requiring ICU stay or ventilation support, with infection rarely progressing to lower respiratory tract infections (Hong et al., 2020). We postulate that breast feeding or wide use of Lf containing infant formula in this population may account for the above observation (Chang \& Sun, 2020) but this remains to be validated.

Another interesting observation is that zinc saturated lactoferrin can apparently exert a more potent antiviral effect. In experiments with polio virus, it was observed that only zinc lactoferrin, and not iron inhibited viral infection when incubated with the cells after viral attachment, and the inhibition directly correlated with the degree of zinc saturation (Marchetti et al., 1999). This is of particular relevance in COVID-19 as zinc supplementation has been proposed as a possible supplemental intervention for the disease (Zhang \& Liu, 2020).

As there is currently neither established treatment regimen for COVID-19 nor established preventative for SARS-CoV-2, one can contemplate the use of Lf both as a non-toxic health supplement to prevent as well as an adjunct treatment for those who have developed COVID-19. Its successful combined use to enhance conventional antiviral drug treatment in viral disease has been demonstrated against HCV (Kaito et al., 2007) and its potential to reduce mortality due to cytokine induced inflammation and respiratory failure in severe COVID-19 is also suggested by laboratory, animal and clinical studies.

\section{Conclusion}

Much progress has been achieved to elucidate the multifaceted function of lactoferrin (Lf) in the past 30 years as an antiviral as well as a unique anti-inflammatory and immunomodulatory molecule. We have presented the experimental as well as clinical rationale for its use for COVID-19, but further experiments to verify its inhibition of the virus and clinical trials to elucidate dosage and efficacy are necessary to confirm the potential of Lf for SAR-CoV-2 prevention as well as COVID-19 treatment.

\section{Declaration: The authors declare no conflicts of interests}

\section{References}

Actor, J. K., Hwang, S.-A., \& Kruzel, M. L. (2009). Lactoferrin as a natural immune modulator. Current Pharmaceutical Design ,15 (17), 1956-1973. https://doi.org/10.2174/138161209788453202

Andersen, J. H., Jenssen, H., Sandvik, K., \& Gutteberg, T. J. (2004). Anti-HSV activity of lactoferrin and lactoferricin is dependent on the presence of heparan sulphate at the cell surface. Journal of Medical Virology . https://doi.org/10.1002/jmv.20171

Baveye, S., Elass, E., Mazurier, J., Spik, G., \& Legrand, D. (1999). Lactoferrin: A multifunctional glycoprotein involved in the modulation of the inflammatory process. Clinical Chemistry and Laboratory Medicine . https://doi.org/10.1515/CCLM.1999.049

Behrens, E. M., \& Koretzky, G. A. (2017). Review: Cytokine Storm Syndrome: Looking Toward the Precision Medicine Era. Arthritis \& Rheumatology (Hoboken, N.J.) , 69 (6), 1135-1143. https://doi.org/10.1002/art.40071

Bone, R. C., Balk, R. A., Cerra, F. B., Dellinger, R. P., Fein, A. M., Knaus, W. A., Schein, R. M., \& Sibbald, W. J. (1992). Definitions for sepsis and organ failure and guidelines for the use of innovative therapies in sepsis. The ACCP/SCCM Consensus Conference Committee. American College of Chest Physicians/Society of Critical Care Medicine.Chest, 101 (6), 1644-1655. https://doi.org/10.1378/chest.101.6.1644

Bruni, N., Capucchio, M. T., Biasibetti, E., Pessione, E., Cirrincione, S., Giraudo, L., Corona, A., \& Dosio, 
F. (2016). Antimicrobial activity of lactoferrin-related peptides and applications in human and veterinary medicine. Molecules (Basel, Switzerland), 21 (6). https://doi.org/10.3390/molecules21060752

Burckhardt, C. J., \& Greber, U. F. (2009). Virus movements on the plasma membrane support infection and transmission between cells. InPLoS Pathogens . https://doi.org/10.1371/journal.ppat.1000621

Chang, R., Sun,WZ. Lactoferrin may reduce the incidence and attenuate the severity of COVID-19 in infants and children . Preprint at:https://doi.org/10.22541/au.158586333.32247750(2020)

Chen, Y., Liu, Q., \& Guo, D. (2020). Emerging coronaviruses: Genome structure, replication, and pathogenesis. In Journal of Medical Virology . https://doi.org/10.1002/jmv.25681

de Haan, C. A. M., Li, Z., te Lintelo, E., Bosch, B. J., Haijema, B. J., \& Rottier, P. J. M. (2005). Murine coronavirus with an extended host range uses heparan sulfate as an entry receptor. Journal of Virology . https://doi.org/10.1128/jvi.79.22.14451-14456.2005

Egashira, M., Takayanagi, T., Moriuchi, M., \& Moriuchi, H. (2007). Does daily intake of bovine lactoferrincontaining products ameliorate rotaviral gastroenteritis? Acta Paediatrica, International Journal of Paediatrics . https://doi.org/10.1111/j.1651-2227.2007.00393.x

Fung, S.-Y., Yuen, K.-S., Ye, Z.-W., Chan, C.-P., \& Jin, D.-Y. (2020). A tug-of-war between severe acute respiratory syndrome coronavirus 2 and host antiviral defence: lessons from other pathogenic viruses.Emerging Microbes $\mathcal{E}$ Infections , 9 (1), 558-570. https://doi.org/10.1080/22221751.2020.1736644

Guntupalli, K., Dean, N., Morris, P. E., Bandi, V., Margolis, B., Rivers, E., Levy, M., Lodato, R. F., Ismail, P. M., Reese, A., Schaumberg, J. P., Malik, R., \& Dellinger, R. P. (2013). A Phase 2 Randomized, Double-Blind, Placebo-Controlled Study of the Safety and Efficacy of Talactoferrin in Patients With Severe Sepsis*.Critical Care Medicine , 41 (3), 706-716. https://doi.org/10.1097/CCM.0b013e3182741551

Hoffmann, M., Kleine-Weber, H., Schroeder, S., Krüger, N., Herrler, T., Erichsen, S., Schiergens, T. S., Herrler, G., Wu, N.-H., Nitsche, A., Müller, M. A., Drosten, C., \& Pöhlmann, S. (2020). SARS-CoV-2 Cell Entry depends on ACE2 and TMPRSS2 and is blocked by a clinically proven protease inhibitor. Cell . https://doi.org/10.1016/j.cell.2020.02.052

Hong, H., Wang, Y., Chung, H.-T., \& Chen, C.-J. (2020). Clinical characteristics of novel coronavirus disease 2019 (COVID-19) in newborns, infants and children. Pediatrics and Neonatology . https://doi.org/10.1016/j.pedneo.2020.03.00

Ishikado, A., Imanaka, H., Takeuchi, T., Harada, E., \& Makino, T. (2005). Liposomalization of lactoferrin enhanced it's anti-inflammatory effects via oral administration. Biological \&3 Pharmaceutical Bulletin, 28 (9), 1717-1721. https://doi.org/10.1248/bpb.28.1717

Johanson, B., Virtanen, A. I., Tweit, R. C., \& Dodson, R. M. (1960). Isolation of an iron-containing red protein from human milk. Acta Chemica Scandinavica . https://doi.org/10.3891/acta.chem.scand.14-0510

Jolles, J., Mazurier, J., Schoentgen, F., Legrand, D., Spik, G., Montreuil, J., \& Jolles, P. (1984). Human lactotransferrin : amino acid sequence and structural comparisons with other transferrins. European Journal of Biochemistry .

Kaito, M., Iwasa, M., Fujita, N., Kobayashi, Y., Kojima, Y., Ikoma, J., Imoto, I., Adachi, Y., Hamano, H., \& Yamauchi, K. (2007). Effect of lactoferrin in patients with chronic hepatitis C: combination therapy with interferon and ribavirin. Journal of Gastroenterology and Hepatology , 22 (11), 1894-1897. https://doi.org/10.1111/j.1440-1746.2007.04858.x

Kruzel, M L, Harari, Y., Chen, C. Y., \& Castro, G. A. (2000). Lactoferrin protects gut mucosal integrity during endotoxemia induced by lipopolysaccharide in mice. Inflammation , 24 (1), 33-44. https://doi.org/10.1023/a:10069359089

Kruzel, Marian L, Actor, J. K., Radak, Z., Bacsi, A., Saavedra-Molina, A., \& Boldogh, I. (2010). Lactoferrin decreases LPS-induced mitochondrial dysfunction in cultured cells and in animal endotoxemia model. Innate Immunity , 16 (2), 67-79. https://doi.org/10.1177/1753425909105317 
Kruzel, Marian L, Zimecki, M., \& Actor, J. K. (2017). Lactoferrin in a context of inflammation-induced pathology. Frontiers in Immunology , 8 , 1438. https://doi.org/10.3389/fimmu.2017.01438

Kuchler, H., Cookson, C., \& Neville, S. (2020, March 6). The $\$ 2$ bn race to find a vaccine. Financial Times , 7. https://www.ft.com/content/e0ecc6b6-5d43-11ea-b0ab-339c2307bcd4

Lang, J., Yang, N., Deng, J., Liu, K., Yang, P., Zhang, G., \& Jiang, C. (2011). Inhibition of SARS pseudovirus cell entry by lactoferrin binding to heparan sulfate proteoglycans. PloS One , 6 (8), e23710. https://doi.org/10.1371/journal.pone.0023710

Legrand, D., Elass, E., Carpentier, M., \& Mazurier, J. (2006). Interactions of lactoferrin with cells involved in immune function.Biochemistry and Cell Biology . https://doi.org/10.1139/O06-045

Levay, P. F., \& Viljoen, M. (1995). Lactoferrin: a general review.Haematologica , 80 (3), 252-267. http://www.ncbi.nlm.nih.g

Lu, L., Hangoc, G., Oliff, A., Chen, L. T., Shen, R. N., \& Broxmeyer, H. E. (1987). Protective influence of lactoferrin on mice infected with the polycythemia-inducing strain of Friend virus complex. Cancer Research , 47 (15), 4184-4188. http://www.ncbi.nlm.nih.gov/pubmed/3038309

Marchetti, M., Superti, F., Ammendolia, M. G., Rossi, P., Valenti, P., \& Seganti, L. (1999). Inhibition of poliovirus type 1 infection by iron-, manganese- and zinc-saturated lactoferrin. Medical Microbiology and Immunology , 187 (4), 199-204. https://doi.org/10.1007/s004300050093

Mehta, P., McAuley, D. F., Brown, M., Sanchez, E., Tattersall, R. S., Manson, J. J., \& HLH Across Speciality Collaboration, U. (2020). COVID-19: consider cytokine storm syndromes and immunosuppression.Lancet (London, England) . https://doi.org/10.1016/S0140-6736(20)30628-0

Milewska, A., Zarebski, M., Nowak, P., Stozek, K., Potempa, J., \& Pyrc, K. (2014). Human coronavirus NL63 utilizes heparan sulfate proteoglycans for attachment to target cells. Journal of Virology,88 (22), 13221-13230. https://doi.org/10.1128/JVI.02078-14

Ng, T. B., Cheung, R. C. F., Wong, J. H., Wang, Y., Ip, D. T. M., Wan, D. C. C., \& Xia, J. (2015). Antiviral activities of whey proteins.Applied Microbiology and Biotechnology . https://doi.org/10.1007/s00253-015$6818-4$

Nozaki, A., Ikeda, M., Naganuma, A., Nakamura, T., Inudoh, M., Tanaka, K., \& Kato, N. (2003). Identification of a lactoferrin-derived peptide possessing binding activity to hepatitis $\mathrm{C}$ virus $\mathrm{E} 2$ envelope protein. The Journal of Biological Chemistry , 278 (12), 10162-10173. https://doi.org/10.1074/jbc.M207879200

Oda, H., Nakano, M., Wakabayasi, H., Koji, Y., Toida, T., Iwatsuki, K., \& Matsumoto, T. (2012). Questionnaire survey on the subjective effects of a lactoferrin supplement. Japanese Journal of Complementary and Alternative Medicine , 9 (2), 121-128. https://doi.org/10.1625/jcam.9.121

Puddu, P., Borghi, P., Gessani, S., Valenti, P., Belardelli, F., \& Seganti, L. (1998). Antiviral effect of bovine lactoferrin saturated with metal ions on early steps of human immunodeficiency virus type 1 infection. The International Journal of Biochemistry \& Cell Biology , 30 (9), 1055-1062. https://doi.org/10.1016/s1357$2725(98) 00066-1$

Razak, A., \& Hussain, A. (2019). Lactoferrin supplementation to prevent late-onset sepsis in preterm infants: A meta-analysis. American Journal of Perinatology . https://doi.org/10.1055/s-0039-1696676

Rosa, L., Cutone, A., Lepanto, M. S., Paesano, R., \& Valenti, P. (2017). Lactoferrin: A natural glycoprotein involved in iron and inflammatory homeostasis. In International Journal of Molecular Sciences . https://doi.org/10.3390/ijms18091985

Sapp, M., \& Bienkowska-Haba, M. (2009). Viral entry mechanisms: Human papillomavirus and a long journey from extracellular matrix to the nucleus. In FEBS Journal . https://doi.org/10.1111/j.17424658.2009.07400.x 
Siqueiros-Cendon, T., Arevalo-Gallegos, S., Iglesias-Figueroa, B. F., Garcia-Montoya, I. A., Salazar-Martinez, J., \& Rascon-Cruz, Q. (2014). Immunomodulatory effects of lactoferrin. Acta Pharmacologica Sinica , 35 (5), 557-566. https://doi.org/10.1038/aps.2013.200

Soerensen, M, S. S. (1939). The protein in whey. C R Trav Lab Carlsberg , 23 , 55-00.

Spear, P. G. (2004). Herpes simplex virus: Receptors and ligands for cell entry. In Cellular Microbiology . https://doi.org/10.1111/j.1462-5822.2004.00389.x

Vincent, J. L., Marshall, J. C., Dellinger, R. P., Simonson, S. G., Guntupalli, K., Levy, M. M., Singer, M., \& Malik, R. (2015). Talactoferrin in severe sepsis: results from the phase II/III Oral talactoferrin in severe sepsis trial. Critical Care Medicine . https://doi.org/10.1097/CCM.0000000000001090

Vitetta, L., Coulson, S., Beck, S. L., Gramotnev, H., Du, S., \& Lewis, S. (2013). The clinical efficacy of a bovine lactoferrin/whey protein Ig-rich fraction $(\mathrm{Lf} / \mathrm{IgF})$ for the common cold: A double blind randomized study. Complementary Therapies in Medicine . https://doi.org/10.1016/j.ctim.2012.12.006

Wakabayashi, H., Oda, H., Yamauchi, K., \& Abe, F. (2014). Lactoferrin for prevention of common viral infections. In Journal of Infection and Chemotherapy . https://doi.org/10.1016/j.jiac.2014.08.003

Wei, M., Yuan, J., Liu, Y., Fu, T., Yu, X., \& Zhang, Z.-J. (2020). Novel coronavirus infection in hospitalized infants under 1 year of age in China. JAMA . https://doi.org/10.1001/jama.2020.2131

Zhang, L., \& Liu, Y. (2020). Potential interventions for novel coronavirus in China: A systematic review. Journal of Medical Virology, 92 (5), 479-490. https://doi.org/10.1002/jmv.25707

Zhu, N., Zhang, D., Wang, W., Li, X., Yang, B., Song, J., Zhao, X., Huang, B., Shi, W., Lu, R., Niu, P., Zhan, F., Ma, X., Wang, D., Xu, W., Wu, G., Gao, G. F., \& Tan, W. (2020). A novel coronavirus from patients with pneumonia in China, 2019. New England Journal of Medicine ,382 (8), 727-733. https://doi.org/10.1056/NEJMoa2001017

Zimecki, M., Właszczyk, A., Zagulski, T., \& Kübler, A. (1998). Lactoferrin lowers serum interleukin 6 and tumor necrosis factor alpha levels in mice subjected to surgery. Archivum Immunologiae et Therapiae Experimentalis , 46 (2), 97-104. http://www.ncbi.nlm.nih.gov/pubmed/9613707 